\title{
Fatigue behaviour of fibre-reinforced composite T-joints
}

\author{
Ying Wang ${ }^{1}$ and Constantinos Soutis ${ }^{1, *}$ \\ ${ }^{1}$ Faculty of Science and Engineering, The University of Manchester, James Light Building, Manchester, M13NJ, UK
}

\begin{abstract}
In this paper a study was carried out on the fatigue life of fibre-reinforced composite T-joints subjected to a tensile pull-out loading. The composite T-joints have been made of glass fabric infused with epoxy resin using a vacuum assisted resin transfer moulding technique. Methods such as the use of veil layers, tufting techniques and 3D weave have been employed to improve the interlaminar fracture toughness of the composite T-joints. All the tests were conducted in an Instron testing machine using a specially designed test fixture. Fatigue tests were performed in a load control mode with a stress ratio of $\mathrm{R}=$ $\sigma_{\min } / \sigma_{\max }=0.1$. The cyclic loading pattern was a sinusoidal wave with a frequency of $6 \mathrm{~Hz}$. The specimens were cycled at a series of constant maximum load values up to failure. Fatigue loads versus life data for each T-joint type were produced at various maximum applied loads. The $3 \mathrm{D}$ weave $\mathrm{T}$-joints were found to have the best performance in both static and fatigue loading. Increasing the static properties increases fatigue life performance; the increasing rate in fatigue life is changed with the number of stress cycles. The location for the through-thickness reinforcement plays an important role in improving fatigue life of the Tjoints. Fatigue life is significantly improved if the web is reinforced in through-thickness direction. A finite element (FE) failure model was also created using ABAQUS to determine the location where delamination is initiated and its subsequent propagation.
\end{abstract}

\section{Introduction}

T-joints are found in structural components such as skinspar in wind turbine blades and aircraft wings and road vehicles. The wind-turbine blades are often made of composite materials due to their low density and excellent mechanical properties combination of strength, stiffness, fatigue performance and better corrosion resistance than metals [1]. Wind turbine blade failures, when in service are due to various complicated reasons but blade failures account for most accidents and damage to wind turbines [2]. Therefore, it is important to understand the way the composite $\mathrm{T}$-joint fails and develop methods of improving fatigue life performance to enhance the durability of wind turbines.

Failure mode of a composite T-joint has been widely studied by many investigators [3-9]. The initiation of delamination in the composite $\mathrm{T}$-joint is almost always initiated on the joint's corner due to the maximum stresses developed in this region. After crack initiation, the cracks may propagate along the flange-skin bond line only or along both the central line of the web and the flange-skin bond line, depending upon the $\mathrm{T}$-joint reinforced configurations. Therefore, delamination crack propagation behaviour plays an important role in the control of fatigue failure of the T-joint.

To increase the resistance to delamination/crack propagation, through-thickness reinforcements are widely used to prevent the out-of-plane failures. Various techniques, such as stitching/tufting [7, 10-12], interlaminar veils $[13,14]$, knitting [15], 3D weaving [7,
16, 17] and z-pining [18-20] have been developed to improve the properties in the through-thickness direction. Numerical approach such as finite element analysis was also used to model and simulate delamination behaviour in the composite $\mathrm{T}$-joints by a number of investigators [11, 14, 18, 19, 21-24]. A large number of experimental investigations were performed on failure of composite T-joints with the aim to improve thorough-thickness properties.

Many studies [25-30] have been carried out on fatigue failure of composite materials over the past 20 years; a number of scientific and technical issues still need to be resolved, for example, predictive models for determining the strength of the T-joints with various reinforcement configurations have not been satisfactorily developed [16]. There are no in depth studies on fatigue behaviour of fibre-reinforced composite T-joints so for, and it is the subject of the paper.

In this study, a composite $\mathrm{T}$-joint was manufactured as representative element of the blade structure. The composite $\mathrm{T}$-joints have been made of glass fabric infused with epoxy resin using a vacuum assisted resin transfer moulding (RMT) technique. Methods such as the use of veil layers, tufting and $3 \mathrm{D}$ weaving techniques have been utilised to improve delamination resistance. A finite element model was created using ABAQUS that can be used to determine the initiation and propagation of delamination crack in the composite T-joints. Fatigue tests on different $\mathrm{T}$-joint configurations were conducted in earlier work [31] and used to validate the FE model.

\footnotetext{
Corresponding author: constantinos.soutis@manchester.ac.uk
} 
Experimental measurements and FE analysis are presented and discussed in the following sections.

\section{Experimental methods}

\subsection{Composite T-joints}

The composite $\mathrm{T}$-joints were made of glass fabric infused with epoxy resin using a vacuum-assisted RTM technique. The geometry and layup detail of the composite $\mathrm{T}$-joint used as the baseline configuration in the study is shown in Fig. 1(a). The flange and skin parts consist of five layers of equal thickness arranged in a stacking sequence of $\left[45^{\circ} /-45^{\circ}\right]_{5}$ while the web consists of 10-layer $\left[45^{\circ} /-45^{\circ}\right]_{10}$ plate. The stiffener consists of 5layer unidirectional (UD) $\left[0^{\circ}\right]_{5}$, which is used to prevent large deflection that may not be representative of the larger structure. Various techniques such as veil layer, tufting and 3D weave were used to improve interlaminar fracture toughness and are listed in Table 1.

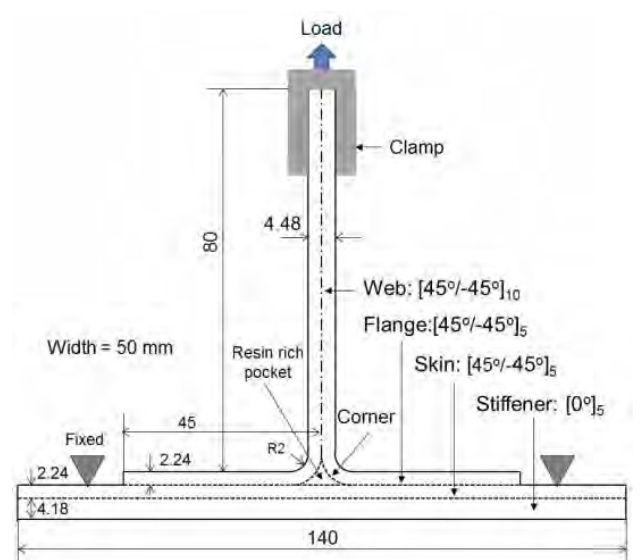

(a)

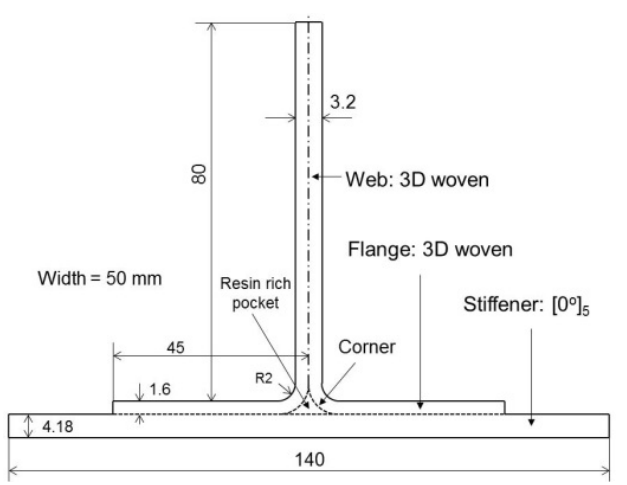

(b)

Fig. 1. Geometry and layup of composite T-joints used (all dimension in $\mathrm{mm}$ )

A non-woven fabric (polyamide/polyester veil) was added between the flange and the skin. The thickness of the veil is $0.055 \mathrm{~mm}$ for polyester and $0.194 \mathrm{~mm}$ for polyamide, respectively.

Tufting material used for out-of-plane stitching was a 120 tex Kevlar-29 thread with tenacity of 185-200 $\mathrm{cN} /$ tex. Stitch density was $10 \mathrm{~mm}$ in the length direction and $10 \mathrm{~mm}$ in the width direction.

Table 1. Test sample specifications

\begin{tabular}{|c|c|}
\hline Type & Descriptions \\
\hline Baseline & T-joint made from glass fibre and epoxy matrix (Fig. 1a) \\
\hline $\begin{array}{c}\text { PA veil } \\
\text { (Polyamide veil) }\end{array}$ & $\begin{array}{c}\text { Type Baseline T-joint + polyamide veil added between the } \\
\text { flange and the skin (Fig. 1a) }\end{array}$ \\
\hline $\begin{array}{c}\text { PE veil } \\
\text { (Polyester veil) }\end{array}$ & $\begin{array}{c}\text { Type Baseline T-joint + polyester veil added between the } \\
\text { flange and the skin (Fig. 1a) }\end{array}$ \\
\hline Tufted & $\begin{array}{c}\text { Type Baseline T-joint + Kevlar thread in through-thickness } \\
\text { direction on flange-skin-stiffener (Fig. 1a) }\end{array}$ \\
\hline 3D-Layer to Layer & T-joint made from 3D Layer to Layer woven fabric (Fig.1b) \\
\hline 3D-Angle Interlock & T-joint made from 3D Angle Interlock woven fabric (Fig.1b) \\
\hline
\end{tabular}

3D woven fabrics, angle interlock and layer to layer, were selected to manufacture the composite $\mathrm{T}$-joints. The fibre type used in the 3D weaves is E-glass. The structure was weaved as a flat panel and from halfway in width the middle layer was removed during the weave process and a gap in thickness produced. The woven panel was then opened up from this gap and the two flange sections of the joint were formed on each sides of the web shown in Fig. 1(b).

The resin is an epoxy based on Araldite LY 564, and the associated hardener used is a formulated amine based on XB 3486. Unidirectional E glass fibre (FGE664) was used for the stiffener (support plate) and $\pm 45^{\circ}$ glass fibre (FGE104) was used in the fabrication of the web, flange and skin of the T-joint. The areal density for $\left[ \pm 45^{\circ}\right]$ and UD fabrics is 609 and $594 \mathrm{~g} / \mathrm{m}^{2}$, respectively.

\subsection{Test condition and procedure}

The T-joint is subjected to tensile pull-out loading along the web. The skin part is considered to be supported near the two ends of the T-joint, as indicated in Fig. 1(a). The mechanical response of different types of T-joints was tested under tensile pull-out loading to obtain the ultimate failure load.

An Instron testing machine was employed to perform the mechanical tests at a loading rate of $2 \mathrm{~mm} /$ minute. Load and displacement values were recorded during tests. A criterion to terminate the test was set as either a $40 \%$ drop in the measured load or a total delamination length of $50 \mathrm{~mm}$

Fatigue test was performed in a load control mode with a stress ratio of $R=\sigma_{\min } / \sigma_{\max }=0.1$. The cyclic loading pattern was a sinusoidal wave at a frequency of 6 $\mathrm{Hz}$ while the thermal effect is not considered at this test frequency. The specimens were cycled at a series of constant maximum load values up to failure. Fatigue load levels were chosen with regards to maximum pullout strength of samples obtained in the static tensile test. This allowed a complete knowledge of the stress-life relationship ( $S-N$ curves) of T-joints with different configurations. Constant fatigue load versus life data for each T- joint type were produced at various constant maximum applied loads. Failure criteria for fatigue tests were either crack length of $25 \mathrm{~mm}$ on each side of the web or one million fatigue cycles. Visual observations of each specimen were also undertaken at intervals during testing, and a record was made of any damage observed. 


\section{Experimental results}

\subsection{Tensile pull-out test}

For fatigue testing it is necessary determine the ultimate tensile pull-out strength (UTS) under static loading. The test results were normalised on the base plate (flangeskin-stiffener) to remove the effect of thickness variation of the base plate. Taking into account the effect of bending, the maximum nominal stress occurring in the base plate is calculated using the beam bending theory [32] and the maximum nominal stress $(\sigma)$ is given by

$$
\sigma=\frac{3 L}{2 b}\left(\frac{P}{h^{2}}\right)
$$

Here $P$ is the applied load, $L$ is the span of T-joint, $h$ is the total thickness of the base section and $b$ is the width of T-joint. When the span ( $L=100 \mathrm{~mm}$ in this case) and the width $(b=50 \mathrm{~mm})$ is fixed the magnitude of the stress occurred on the surface is inversely proportional to the square of the thickness $(h)$.

The nominal stresses $(\sigma)$ calculated by Equation (1) are plotted against the deflections $(\delta)$ and these $\sigma-\delta$ curves are shown in Fig. 2. It can be seen from the figure, the $\sigma-\delta$ behaviour is sensitive to the composite Tjoint architectures. 3D woven $\mathrm{T}$-joint always shows the best pull-out performance compared with other type Tjoints. When the defection is less than a certain value, a linear relationship exists between the deflection and the applied stress produced by the load. The slope of the $\sigma-\delta$ curves is almost the same when the applied stress is less than around $65 \mathrm{MPa}$ for the joints (Baseline, PA veil, PE veil and Tufted T-joints). In other words, the slope (or 'stiffness') appeared in the linear stage is not influenced by the veil layer or tufting. In the $3 \mathrm{D}$ woven $\mathrm{T}$-joint, the slope of the $\sigma-\delta$ curves is almost the same as in that of the $\sigma-\delta$ curves from above type T-joints, although the slope of the $\sigma-\delta$ curve begins to decrease at a higher applied stress, e.g. around $210 \mathrm{MPa}$.

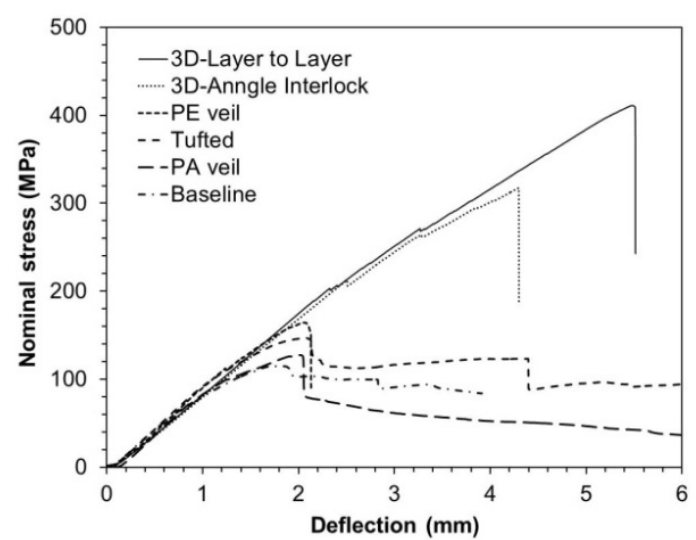

Fig. 2. The $\sigma-\delta$ curves of T-joints from tensile pull-out tests.

The reduction in the curve's slope is associated with initiation of damage developed in the $\mathrm{T}$-joint and it continues until the maximum pull-out load is reached. The applied stress value for the reduction of the curve's slope depends upon the type of the composite T-joint.
The maximum pull-out loads were measured for all $\mathrm{T}$-joints. At least five tests were performed for each type of T-joint. The 3D-layer to layer stitched T-joint shows the highest pull-out strength (417.5MPa) among all the tested specimens and its strength is increased by $254 \%$ when compared to the type Baseline specimen $(117.8 \mathrm{MPa})$. The second is the $3 \mathrm{D}$-angle interlock specimen $(319.8 \mathrm{MPa})$. The third is the PE veil T-joint (169.6MPa) while the PA veil specimen is only 120.9 $\mathrm{MPa}$. The Tufted specimen is $149.6 \mathrm{MPa}$.

The test results confirm that when through-thickness reinforcements (3D woven joint) are used in the web the tensile pull-out strength is significantly increased in comparison with other type T-joints. The samples with the PE veils also show higher strength compared to Baseline type T-joint. The tensile pull-out strength in the tufted specimen is also improved, but much less compared to the $3 \mathrm{D}$ woven specimen in that the tufting yarns are applied only on the flange-skin-stiffener. These results emphasise the importance of the location where through-thickness reinforcements is applied. All these test results provide experimental evidence for the validation of the FE results, which are discussed in later section.

\subsection{Fatigue behaviour}

Fatigue test results in terms of applied stress and number of cycles to failure were plotted for each specimen to produce $S-N$ curves for all type T-joints. Fig. 3 shows the fatigue test results of the Baseline T-joint. The solid line is the best regression fit of the data points with the $R^{2}$ value of 0.789 ; the dotted lines are 95\% upper and lower confidence limits. As expected, increasing the fatigue load decreases the number of cycles to failure.

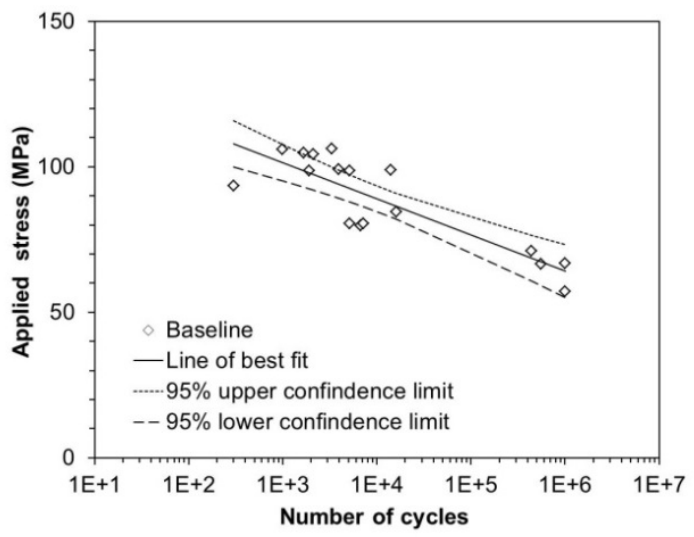

Fig. 3. $S-N$ data for baseline type T-joint.

The $S$ - $N$ curve of the T-joint with a polyamide veil is shown in Fig. 4, along with a regression fit (solid line). The $R^{2}$ value is 0.727 . A few data points are out of $95 \%$ confidence limit band. The result of fatigue tests from the PE veil T-joints is shown in Fig. 5. The $R^{2}$ value is 0.84 .

Fatigue life performance of the tufted $\mathrm{T}$-joints is shown in Fig. 6, where the solid line is the best fit and the dotted lines are 95\% upper and lower confidence limits. The $R^{2}$ value is 0.853 . As can be seen from the figure, some of the test data are located outside $95 \%$ 
confidence limit band. The tufting technique improves delamination resistance resulting from the crack bridging by z-fibres, which reduces the driving force for crack growth. However, the localised fibre damage from the needle penetration and the resin rich pocket at tufted yarns lead to the reduction in fatigue life performance due to its direct interaction with the crack growth path.

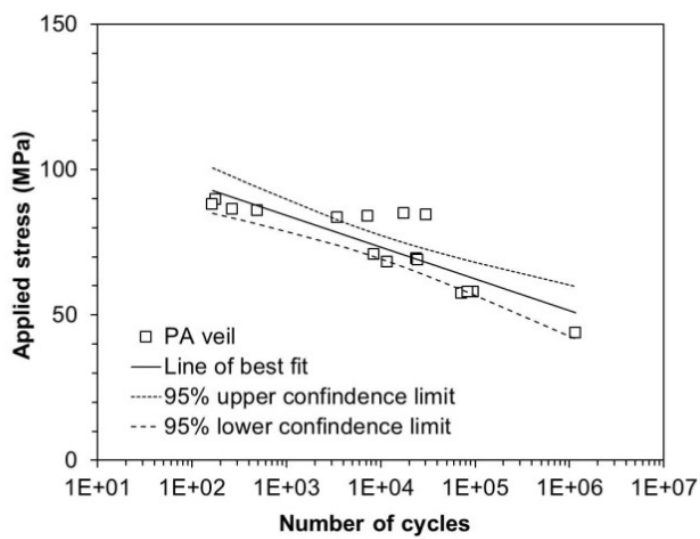

Fig. 4. $S-N$ data for polyamide veil T-joint.

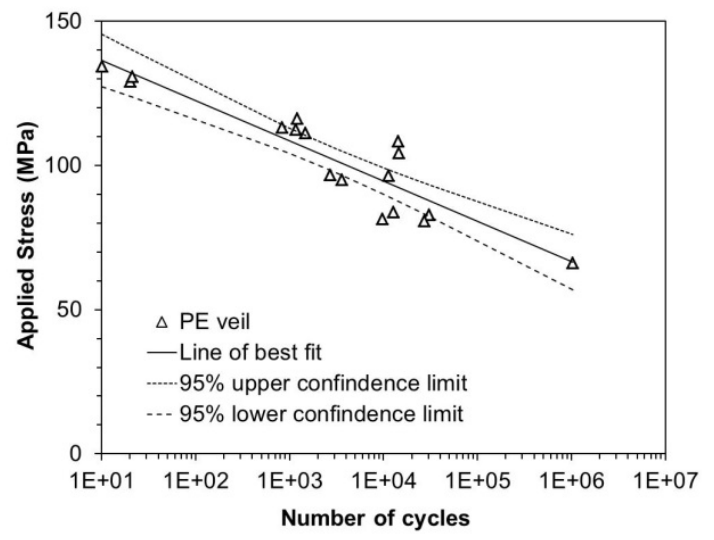

Fig. 5. $S$ - $N$ data for polyester veil T-joint

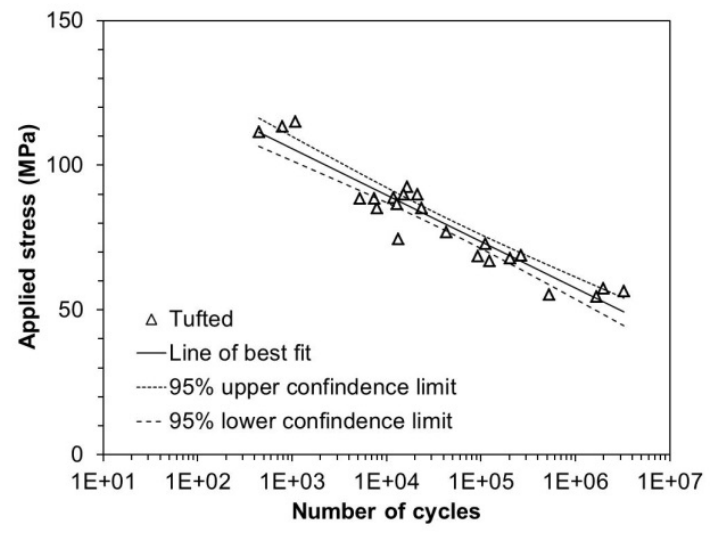

Fig. 6. $S-N$ data for tufted t-joint

Fig. 7 shows fatigue data of the 3D woven specimen made of angle interlock woven structure. Due to limited availability of the 3D angle interlock fabric, the number of fatigue tested specimens was less compared to other structures; however, the low deviation shows the high accuracy of measured values with $R^{2}$ value of 0.976 . Most of the test data are located in $95 \%$ confidence limit band as shown in Fig. 7.

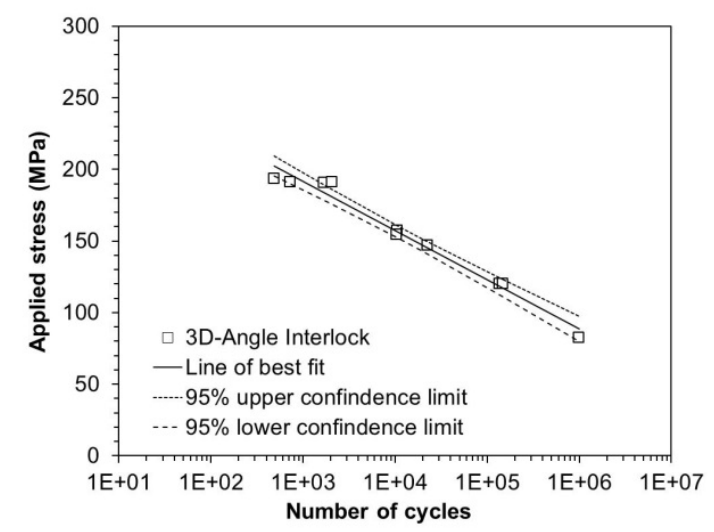

Fig. 7. $S-N$ data for $3 \mathrm{D}$-anagle interlock T-joint.

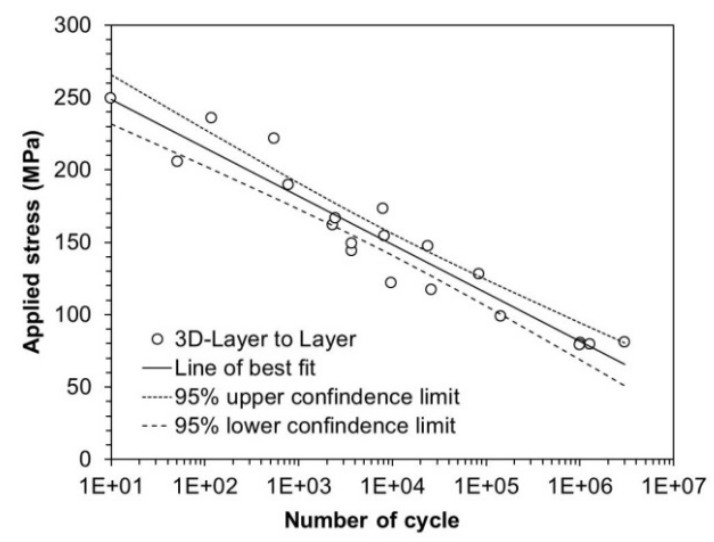

Fig. 8. $S-N$ data for 3D-layer to layer stitched T-joint.

The test result of the 3D woven layer to layer stitched T-joint is shown in Fig. 8, along with a best regression fit (solid line). A number of specimens were tested in very low load levels ( $25 \%$ of tensile pull-out strength) to examine the possibility of failure of the joint in low applied stress and find the fatigue limit of the joint. Most of the tested specimens in this load level did not fail, even after $3 \times 10^{6}$ cycles, which was three times the test limit.

To clearly compare the fatigue behaviour of all types of T-joints, all six sets of data were plotted together shown in Fig. 9, along with a regression fit for each. The results from the static tests were also plotted at cycle number $n=1$. As can be seen, all curves show the same trend. Increasing fatigue load leads to the decrease in the number of cycles to failure. Fatigue strength of the composite $\mathrm{T}$-joints is significantly influenced by reinforcement configurations.

The best fatigue life performance is clearly seen in 3D- woven T-joint with almost $40-80 \%$ improvement in fatigue life, depending on the stress cycles. The use of inter-laminar veil is also able to increase T-joint fatigue strength, but not very significant. The tufting or stitching may cause localised fibre damage from the needle penetration and discontinuity at the stitching point; the resin rich pocket is created due to the presence of tuft yarns and therefore the micro-cracks are easily to be produced.

Taking to account the deviation of data and statistical analysis, it was found that there is no significant difference in fatigue performance for Baseline, PE veil 
and tufted T-joints as the $95 \%$ confidence limit bands of these data were overlapped quite significantly. However $3 \mathrm{D}$ woven $\mathrm{T}$-joints show a good improvement in fatigue properties while the polyamide veil reduces fatigue properties of the PA veil T-joint.

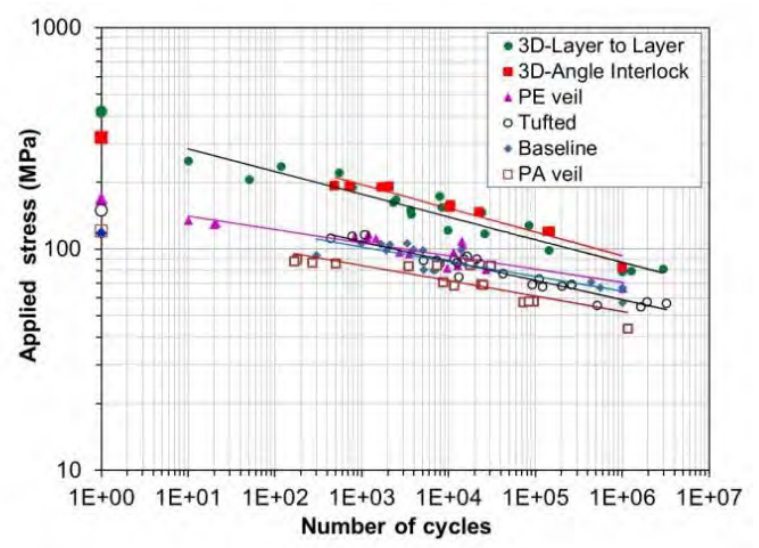

Fig. 9. Comparison of $S-N$ curve for al type T-joint specimens.

Comparison of static and fatigue test results showed that they are not always in agreement. For instance 3Dlayer to layer T-joint, which had the highest pull-out strength, did not perform well under fatigue loading and the 3D woven angle interlock structure performed best. However, when all test results were considered, a relatively good agreement between static and fatigue results was seen.

\section{FE modelling of composite T-joints}

\subsection{T-joint FE model}

The T-joint FE model was created using ABAQUS software [33]. The geometry of T-joints used for FE model is as the same as that used in the experimental tests (Figure 1a). Two types of local coordinate systems are used to describe the orientations of each ply. On the corner the cylindrical coordinate system is used. In this coordinate system, the 1,2 , and 3 directions refer to the radial $(\mathrm{R})$, circumferential $(\mathrm{T})$, and axial directions $(\mathrm{Z})$, respectively. In the web, flange, skin and stiffener the rectangle coordinate system is used and the 1,2 , and 3 directions refer to the $\mathrm{X}, \mathrm{Y}$ and $\mathrm{Z}$, respectively. For both coordinate systems, the fibre direction is oriented along axis 2 while directions 1 and 3 correspond to thickness and width directions, respectively (see Fig. 10). Under this coordinate system the engineering constants for the composite material are listed in Table 2. The elastic modulus and Poisson's ratio for the epoxy resin are equal to $4 \mathrm{GPa}$ and 0.34 , respectively.

Table 2. Composite material properties

\begin{tabular}{|c|c|c|c|c|c|c|c|c|}
\hline $\begin{array}{c}E_{1} \\
(\mathrm{GPa})\end{array}$ & $\begin{array}{c}E_{2} \\
(\mathrm{GPa})\end{array}$ & $\begin{array}{c}E_{3} \\
(\mathrm{GPa})\end{array}$ & $v_{12}$ & $v_{13}$ & $v_{23}$ & $\begin{array}{c}G_{12} \\
(\mathrm{GPa})\end{array}$ & $\begin{array}{c}G_{13} \\
(\mathrm{GPa})\end{array}$ & $\begin{array}{c}G_{23} \\
(\mathrm{GPa})\end{array}$ \\
\hline 9 & 38 & 9 & 0.071 & 0.3 & 0.3 & 3.6 & 3.46 & 3.6 \\
\hline
\end{tabular}

The FE simulations were run under displacementcontrolled loading by applying an increasing tensile displacement along the web. To simulate the fixture roller bars, the skin surface is considered to be restricted in the vertical direction at both sides of the web with 50 $\mathrm{mm}$ distance from the centre. Three elements were used in the thickness direction and an eight-node linear brick element (C3D8R) was utilised. The detailed mesh of the model with the kinematic and loading boundary conditions is shown in Fig. 10.

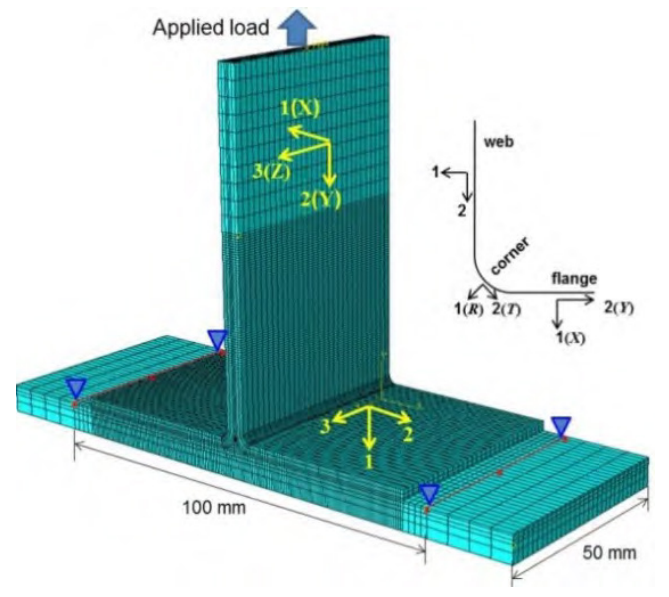

Fig. 10. Mesh, boundary conditions and local coordinate system of the T-joint FE model.

\subsection{Modelling of delamination}

Delamination is modelled using cohesive zone elements. Linear elastic traction-separation behaviour is used to model the interface where the delamination is expected to occur. The traction-separation model in ABAQUS assumes initially linear elastic behaviour followed by damage initiation and evolution.

The initiation of delamination damage can be estimated using the quadratic nominal stress criterion defined by the following expression [33]

$$
\left\{\frac{\left\langle t_{n}\right\rangle}{t_{n}^{0}}\right\}^{2}+\left\{\frac{t_{s}}{t_{s}^{0}}\right\}^{2}+\left\{\frac{t_{t}}{t_{t}^{0}}\right\}^{2}=1
$$

where $t_{n}^{0}$ is the interlaminar normal tensile strength, $t_{s}^{0}$ and $t_{t}^{0}$ are shear strengths in the two transverse directions.

Delamination crack growth is described using a linear softening fracture-based law, where a mixed mode fracture energy criterion is used. Failure under mixedmode conditions is governed by a power law interaction of the energies required to cause failure in the individual modes. It is given by the following expression [33]

$$
\left\{\frac{G_{n}}{G_{n}^{c}}\right\}^{\alpha}+\left\{\frac{G_{s}}{G_{s}^{c}}\right\}^{\alpha}+\left\{\frac{G_{t}}{G_{t}^{c}}\right\}^{\alpha}=1
$$

where $G_{n}^{c}$ is the normal strain energy release rate, $G_{s}^{c}$ and $G_{t}^{c}$ are shear strain energy release rates in the two transverse directions; $\alpha$ is assumed to be equal to 1 , but could be 2 . The effect of $\alpha$ value on the load-deflection curve was studied and the variation of $\alpha$ values shows less effect. Various fracture energy values are selected to 
investigate its effect on crack propagation. Selecting 'appropriate' stress-based or fracture-based remains a debating issue.

\section{Numerical results}

\subsection{Stress distribution with T-joint geometry}

The numerical analysis has confirmed that the maximum stresses are developed at the interface between the corner and resin (arc BC in Fig. 11(a)). The magnitude of these stresses is influenced by the parameters such as the radius of the corner $(r)$ and the thickness of the plate $(h)$.

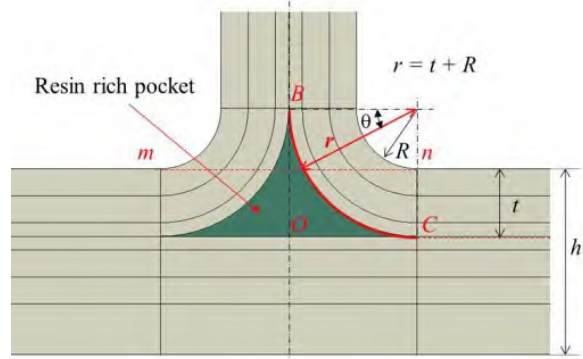

(a)

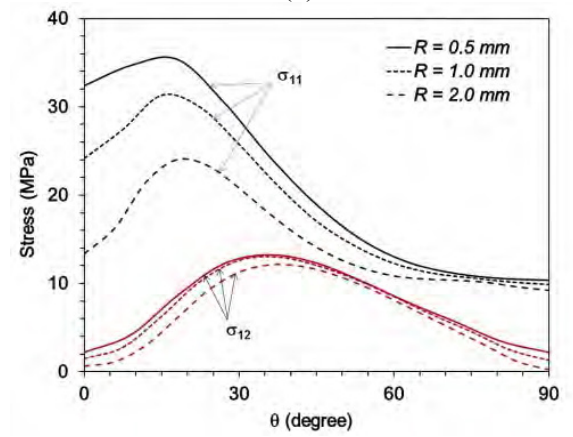

(b)

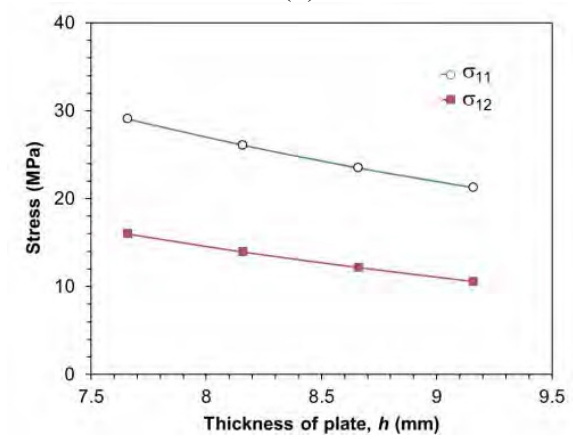

(c)

Fig. 11. Diagrams showing: (a) geometrical parameters of $T$ joint; (b) effect of corner radius on stress distribution along the arc $\mathrm{BC} ;(\mathrm{c})$ effect of thickness on the maximum stress $\left(\sigma_{11}\right)$.

The distribution of the stress $\left(\sigma_{11}\right)$ is significantly influenced by the curvature of the corner as shown in Fig. 11(b). As can be seen from the figure, the maximum stress $\left(\sigma_{11}\right)$ is increased by $40 \%$ when the radius $R$ is reduced from $2 \mathrm{~mm}$ to $0.5 \mathrm{~mm}$. However, there is no significant effect on the shear stress $\left(\sigma_{12}\right)$ shown in Fig. 11(b), indicated by red colour lines.

The stress at the corner is sensitive to the thickness of the base plate. Fig. 11(c) demonstrates the relationship between the thickness and the maximum stresses occurred at the corner. For example, $11.3 \%$ increase (from 7.66 to $8.66 \mathrm{~mm}$ ) in the thickness $(h)$ results in $19.1 \%$ decrease in stress $\sigma_{11}$ and $23.8 \%$ decrease in stress $\sigma_{12}$, respectively.

\subsection{Effect of through-thickness reinforcement in the web}

When the web has through thickness reinforcements the tensile pull-out strength is significantly increased in both static and fatigue loading. With this reinforced structure, crack propagation was only along the bonded connection between skin and flange; no crack growth was seen in the web as shown in Fig. 12(a). The crack is inhabited to propagate in the web due to the nature of reinforcements.

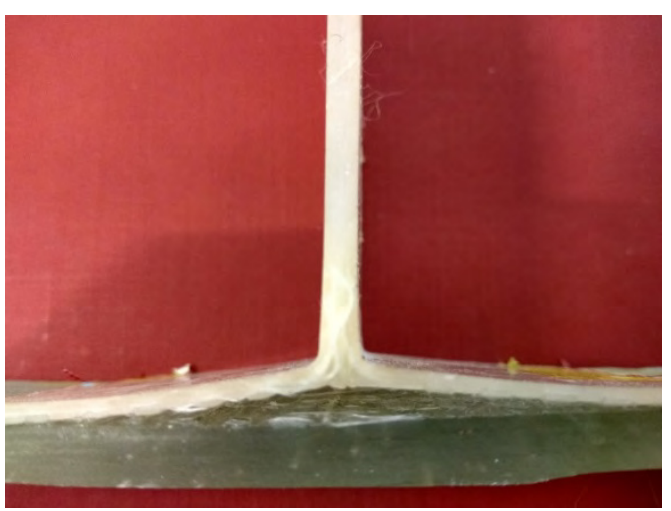

(a)

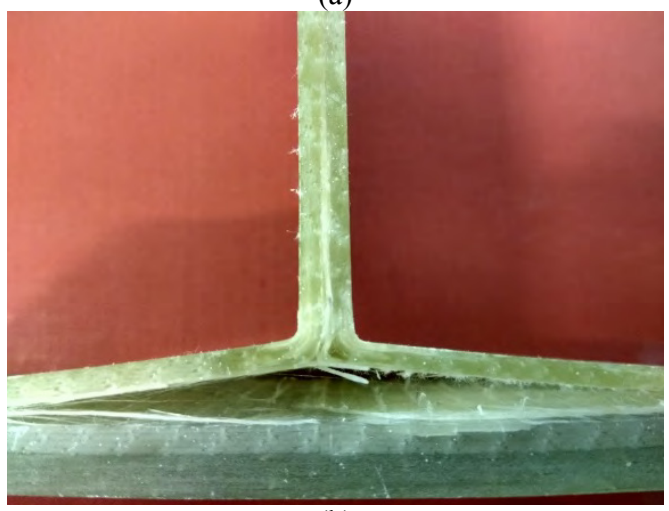

(b)

Fig. 12. (a) No crack growth occurs in the web for $3 D$ woven $\mathrm{T}$-joints and the crack grows only along the flange-stiffener bond line. (b) Crack growth is along the central line of web and the flange-skin bond line if no reinforced fibre in the web through thickness direction.

To model crack growth in the $3 \mathrm{D}$ woven $\mathrm{T}$-joints, a tie constraint was imposed between pairs of surfaces (the central line of the web), instead of cohesive zone element, to simulate its structural feature. In this way, there is no crack propagation along the central line of the web and the crack propagation is along the flangestiffener bonding line only. This approach reflects the experimental observations from the $3 \mathrm{D}$ woven $\mathrm{T}$-joints.

The experimental observations showed that the crack propagation path was similar in both static and fatigue tested T-joints. The crack was initiated at the corner for both cases. For the T-joints with no through-thickness reinforcements in the web, after initial propagation in the web the crack propagation slowed down and then started 
to propagate along the interface between the flange and skin. This failure mode is applicable to Baseline, PA veil, PE veil and Tufted T-joints. Fig. 12(b) just shows an example of tested $\mathrm{PE}$ veil type T-joint.

FE simulation results are shown in Fig. 13. As can be seen from the figure, the maximum load to failure is significantly increased when the web is reinforced in the through thickness direction. The maximum load to failure is increased by $90 \%$. This is fairly consistent with the experimental observations of tensile pull-out testing, although it remains difficult to accurately capture all the non-linearities and fluctuations seen in the measured load-deflection response.

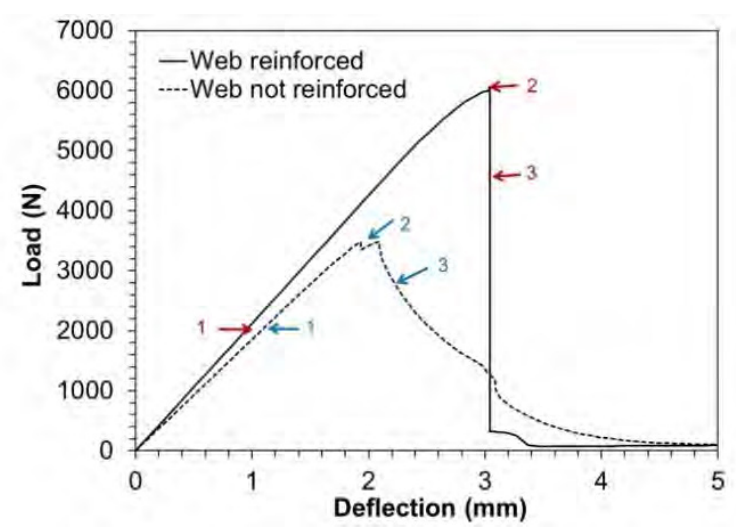

Fig. 13. Load-deflection curve shows that the failure load is significantly increased when the web has through-thickness reinforcements.

The simulated T-joint is framed at different phases of load to numerically investigate damage processes and delamination behaviour. Three levels of load are selected, indicated by the arrows in Fig. 13 (red: web reinforced and blue: web not reinforced). The simulated results are shown in Figures 14 and 15.

Comparison of these two cases reveals that the crack is initiated at the interface between the corner and resin as the high stress developed here. This is highly consistent with the experimental observations. After crack initiation, it continues to propagate in the web along the central line (Fig. 14(a)) when the web does not have through-thickness reinforcements while the crack is hardly to propagate in the web when through thickness reinforcement are applied (Fig. 15(a)).

The crack is propagated further with the increase of applied load. The simulated crack growth at the maximum load is shown in Fig. 14(b), where the web has no through-thickness reinforcements. Fig. 15(b) shows that the crack propagation is increased further along the bond line at the maximum applied load. After the maximum load the crack continues to grow with a big drop in the applied loads and the simulated images for these two cases are shown in Figs. 14(c) and 15(c), respectively.

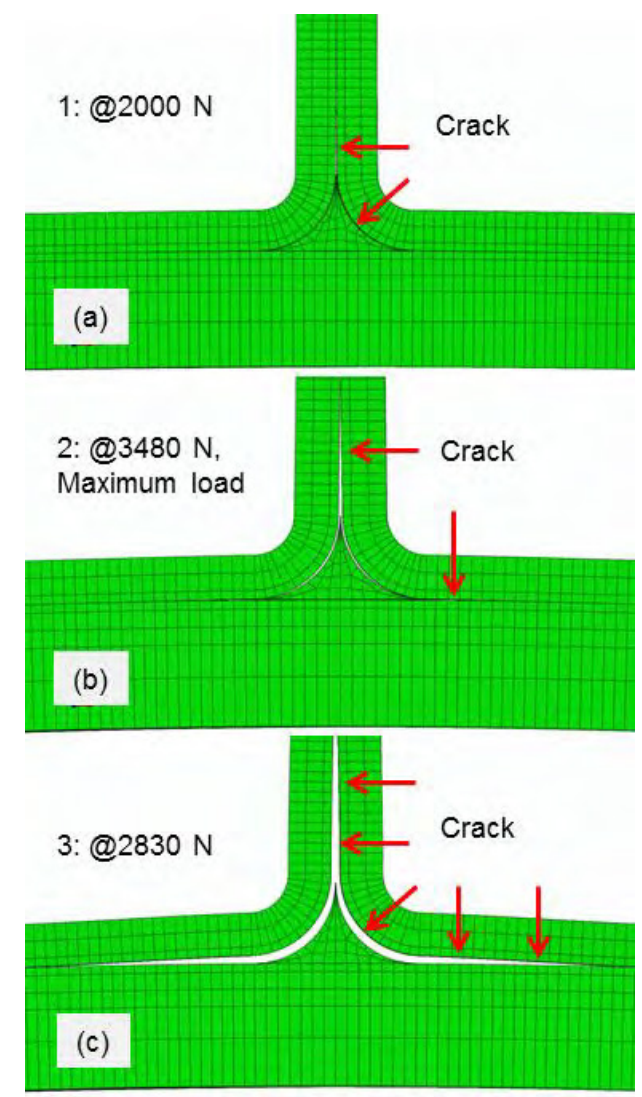

Fig. 14. Simulated images showing damage processes of Tjoints without through-thickness reinforcements.

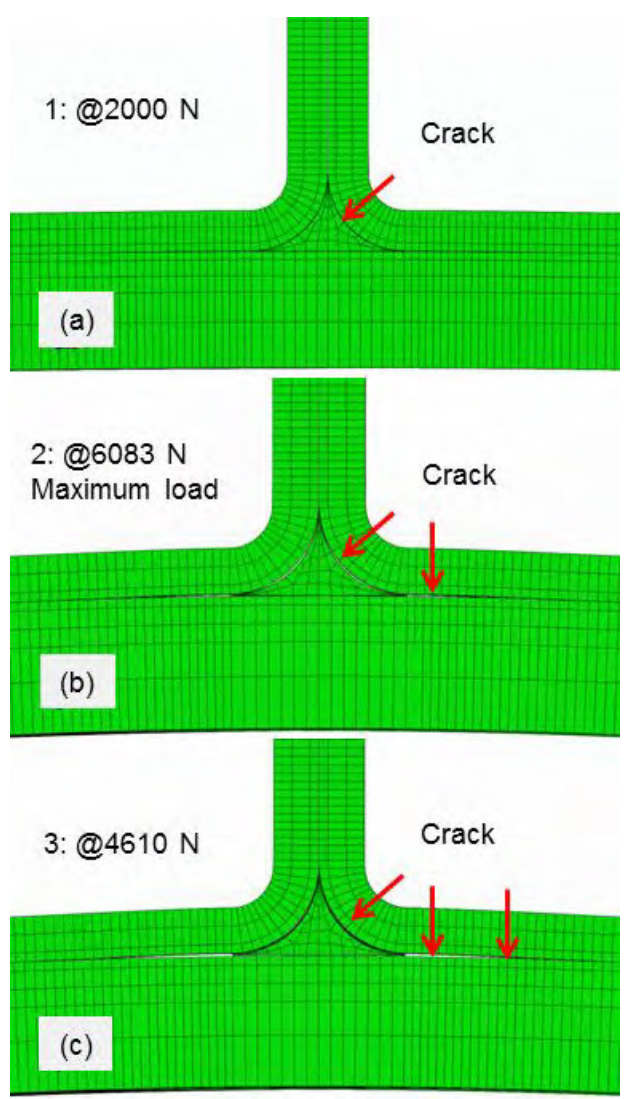

Fig. 15. Simulated images showing damage processes of Tjoints with through-thickness reinforcements. 


\section{Conclusions}

A comprehensive study was carried out on fatigue failure mode of fibre-reinforced composite T-joints subjected to a tensile pull-out loading. Fatigue tests were performed on four groups of composite T-joints including baseline, inter-laminar veil, tufting and $3 \mathrm{D}$ weaving to investigate its failure mechanisms. A finite element failure model was created using ABAQUS which was used to simulate the mechanical response of the T-joint. The main observations from the present study are as follows:

1. 3D woven type T-joints always show the best performance in both static and fatigue loading. Increasing the static properties increases fatigue performance and a good agreement was seen between the static and fatigue strength.

2. The application of through-thickness reinforcements into the web is very important to improve fatigue strength in that it habits fatigue crack growth in the web and this leads to slow crack growth in the flange-skin region as the driving force for crack growth is significantly reduced if the crack does not exist in the web. This has been confirmed by the FE simulations.

3. In the flange-skin-stiffener region, through-thickness reinforcements (e.g. tufted T-joint) do not improve the fatigue life performance of the T-joint, although the tensile pull-out strength is increased by $27 \%$ compared to Baseline type T-joint.

4. Selecting the proper inter-laminar veil (e.g. polyester veil) may increase the fatigue life performance of the T-joints, but not significantly, although the ultimate strength under a tensile pull-out loading is increased significantly. Fatigue life performance is reduced for the $\mathrm{T}$-joint containing the polyamide veil.

5. An FE failure analysis model was developed which can be used to determine delamination behaviour of composite T-joints under a tensile pull-out loading. The FE predictions were validated by experimental measurements and observations.

\section{References}

1. E. Sesto and C. Casale, J Wind Eng Ind Aerod. 7476:375-387 (1998)

2. J.-S. Chou and W.-T. Tu, Eng Fail Anal 18:295-313 (2011)

3. R.A. Shenoi and G.L. Hawkins, Composites. 23(5):335-345 (1992)

4. V.V.S. Rao, K.K. Veni, and P.K. Sinha, Aircr Eng Aerosp Tec. 76(4):404-413 (2004)

5. A.R. Rispler, G.P. Steven, and L. Tong, J Reinf Plast Comp. 16(18):1642-1658 (1997)

6. J.I.R. Blake, R.A. Shenoi, J. House, and T. Turton, Composites Part A. 32:641-653 (2001)
7. D.D.R. Cartie, G. Dell'Anno, E. Poulin, and I.K. Partridge, Eng Fract Mech. 73:2532-2540 (2006)

8. F. Dharmawan, R.S. Thomson, H. Li, I. Herszberg, and E. Gellert, Compos Struct. 66:181-187 (2004)

9. L. Burns, A. Mouritz, D. Pook, and S. Feih, Composites Part A. 43(11):1971-1980. (2012)

10. A.P. Mouritz, K.H. Leong, and I. Herszberg, Composites Part A. 28(12):979-991 (1997)

11.Y. Wang and C. Soutis, Engineering and Computational Mechanics 169(EM4):158-170 (2016)

12. K. Dransfield, C. Baillie, and Y.-W. Mai, Compos Sci Technol. 50(3):305-317 (1994)

13. M. Kuwata and P.J. Hogg, Composites Part A 42(10):1551-1559 (2011)

14. Y. Wang, C. Soutis, A. Hajdaei, and P.J. Hogg, Plast Rubber Compos. 44(3):87-97 (2015)

15. K. Leong, S. Ramakrishna, Z. Huang, and G. Bibo, Composites Part A. 31(3):197-220 (2000)

16. A.P. Mouritz, M.K. Bannister, P.J. Falzon, and K.H. Leong, Composites Part A. 30(12):1445-1461 (1999)

17. B.N. Cox, M.S. Dadkhah, W.L. Morris, and J.G. Flintoff, Acta Metall Mater. 42(12):3967-3984 (1994)

18. G. Allegri and J. Zhang, Composites Part A. 38(4):1107-1115 (2007)

19. F. Bianchi, T.M. Koh, X. Zhang, I.K. Partridge, and A.P. Mouritz, Compos Sci Technol 73:48-56 (2012)

20. A.P. Mouritz, Composites: Part A. 38(12):2383-2397 (2007)

21. A. Baldi, A. Airoldi, M. Crespi, P. Iavarone, and P. Bettini, Procedia Engineering 10:3483-3489 (2011)

22.F. Bianchi and X. Zhang, Compos Sci Technol. 71:1898-1907 (2011)

23. J. Chen, Fatigue Fract Eng M. 34:123-130 (2010)

24. J. Chen, E. Ravey, S. Hallett, M. Wisnom, and M. Grassi, Compos Sci Technol. 69(14):2363-2367 (2009)

25. R.A. Shenoi, P.J.C.L. Read, and G.L. Hawkins, Int J Fatigue. 17(6):415-426 (1995)

26. P.J.C.L. Read and R.A. Shenoi, Int J Fatigue 21:281296 (1999)

27. V. Marcadon, Y. Nadot, A. Roy, and J.L. Gacougnolle, Int J Adhes Adhes. 26:481-489 (2006)

28. J. Degrieck and W.V. Paepegem, Appl Mech Rev. 54(4):279-300 (2001)

29. B.L.V. Bak, C. Sarrado, A. Turon, and J. Costa, Appl Mech Rev. 66(11):060803-1-14 (2014)

30. Y. Wang and C. Soutis, Appl Compos Mater. 24:461-475 (2017)

31. A. Hajdaei, Extending the Fatigue Life of a T-joint in a Composite Wind Turbine Blade, in School of Materials. $\quad \mathrm{PhD}$ Thesis, The University of Manchester (2014)

32. A.C. Ugural and S.K. Fenster, Advanced Strength and Applied Elasticity (1995)

33. ABAQUS Analysis User's Manual (2016) 